\title{
Brujas e inquisidores en la América colonial (1569-1820)
}

\author{
Juan BLÁzQuez Miguel.
}

Brujas, demonios, hechiceras, supersticiones varias, de todo tipo y forma, seres, objetos y conjuros que abren las puertas a las fuerzas de otros mundos oscuros, ignotos y presentidos en lo más profundo del subconsciente colectivo humano, no importa qué época, cultura o raza. La Iglesia, como antes tantas fuerzas fácticas, políticas o religiosas, siempre consideró a todo esto como algo peligroso, un enemigo al que había que combatir hasta su exterminio, sin que, por lo general, hasta la fecha lo haya conseguido. Tan sólo la cultura ha arrinconado como trastos viejos alguna que otra particularidad, que más que infernal o paranormal era, simplemente, ridícula e impropia de seres pensantes con un mínimo de raciocinio, pero, aúrı hoy, persisten creencias, e incluso convencimientos, en tantas y tantas mancias a las que es prácticamente imposible desligar de la vida cotidiana.

En América a la llegada de los españoles existía una antiquísima tradición mágica, íntimamente relacionada en muchas ocasiones con la religión o la medicina y los hispanos que a sus costas arribaban llevaban con ellos, además de sus enseres, una carga especial: la de sus tradiciones religiosas y supersticiosas ${ }^{1}$.

Hubiera parecido lógico un sincretismo entre éstas y las aborígenes, pero no fue así normalmente. Los europeos continuaron aferrados a las que habían dejado allende el océano y los indígenas tenían su propia idiosincrasia mágica como para interesarse por algo que les era religiosa, cultural y mágicamente ajeno. De todas formas, si en tan sólo contadas ocasiones determinada bruja o hechicera recurre a algún conjuro o pócima india - problema aparte es el consumo de determinadas drogas, pero 
preciso es considerar que drogas también utilizaban las brujas y hechiceras en España y aquí lo único que hicieron fue adaptarse a las existentes-, son muchos más los indios que empleaban los conjuros hispanos, muy probablemente por considerarlos superiores, pues superiores en todos los aspectos eran para ellos quienes los utilizaban.

\section{LA PRESENCIA DE SATANÁS Y SUS SIERVAS EN AMÉRICA}

Los antiguos ídolos indios estaban considerados por los religiosos españoles como representaciones del diablo, y cualquier superstición, magia o curación llevadas a cabo por los nativos, obras del Maligno eran. Pero, de todas maneras, Satanás, el Satanás combatido por la Iglesia desde el mismo momento de su creación, el enemigo de Cristo, da señales de vida de vez en cuando por tierras americanas. En los años treinta del siglo XVII aparecen dos importantes focos demoníacos en Nueva Granada, cronológicamente paralelos; uno en Tolú, siendo algunas de sus implicadas españolas y ricas, y otro, mucho más interesante, en la propia Cartagena, compuesto de negros y mulatos, que los inquisidores Domingo Vélez y Manuel de Cortázar consideraron como algo real y verdaderamente demoníaco ${ }^{2}$ y éste será el que con algún detenimiento vamos a ver.

Era Cartagena de Indias el mayor puerto receptor y exportador de negros de toda América, por lo que tuvo la mayor concentración de esclavos de este continente ${ }^{3}$. Había lugares, como en las minas antioqueñas o en Zaragoza, que en poco más de diez años llegaron a trabajar 6.000 esclavos ${ }^{4}$. La única liberación para estos desgraciados, aparte de la muerte, era el echarse al monte, hacerse cimarrones y llevar una vida desesperada, salpicada de robos, violaciones y asesinatos, cuyo final presumible era la horca, ya que se llegaba a ofrecer por las autoridades diez pesos al que prendiera o entregara uno de ellos ${ }^{5}$. Los inquisidores les consideraban casi como bestias $-y$ ésa era la opinión común-, que apenas tenían de seres humanos la forma y como no deseaban entremezclarse con esa ralea decidieron en 1622 conceder un perdón general para todos y que fuese en adelante la justicia quien se ocupara de ellos ${ }^{6}$.

AHN, Inquisición, libro 1011, fols. 104-106.

3 Palacios, J., La trata de esclavos por Cartagena de Indias. Tunja 1973; Castillo Mathieu, M., "Cartagena, puerto comercial (1533-1800)", Boletín Cultural y Bibliográfico (Bogotá), XVI, 1972, 2.

"Colmenares, G., "La formación de la economía colonial (1500-1740)", Historia Económica de Colombia, dirigida por J.A. Ocampo. Bogotá 1987

5 Lemaltre, E., Historia general de Cartagena. 5 v. Bogotá 1983, 1l, pág. 180.

- AHN, Inquisición, libro 1009, fols. 281-283v., 290-292 y 299-300v. 
Por lo general, los negros eran ignorantes de todo lo religioso cristiano y poco les importaba la misa, si no era como medio para evadirse del trabajo durante un rato ${ }^{7}$.

Esta situación bien la sabían los inquisidores, por lo que siempre se tuvo consideración y benignidad con aquellos que bautizados reincidieron en sus antiguas idolatrías africanas ${ }^{8}$, pero otra cosa muy diferente era el que aceptaran como Señor al Diablo que habian conocido de sus amos, pues los africanos no concebían al demonio tal y como nosotros nos lo imaginamos, habiendo sido tomado prestado de los europeos ${ }^{9}$.

Lo cierto es que se piensa que el diablo está presente en Cartagena de Indias y quince personas, la mayoría negras exclavas u horras, se ven directamente involucradas. Por vez primera, o al menos de forma directa, se conocen los aquelarres en América tal y como se describían en España, $\sin$ apenas variación alguna ${ }^{10}$.

El asunto comienza con Justa, mulata horra al servicio de doña María Ana de Armas, que confesó haber reconocido a Lucifer como su señor, besándole el trasero y bailando a su alrededor con candelillas, cenando alimentos brujeriles y fornicando con él, que le había dado como acompañante a un personaje llamado Nassao. Lo mismo declaró la negra Juana de Mon, Ilamándose su diablo compañero Quita. Ana Juárez, negra libre, asistía a los aquelarres que se celebraban en la estancia de Chambuco, para lo cual se rebozaba con ciertos ungüentos. Otros aquelarres se celebraban detrás del matadero de Cartagena y en los Manzanillos de la Verega o Playa de los Manzanillos.

Es natural que junto a una playa la comida consistiese en pescado frito, - -al contrario de los cadávares descuartizados que normalmente se devoraban en los aquelarres europeos-, aunque, como éstos, estaban condimentados sin sal y apenas tenían gusto.

No hay aquelarre que se precie que no termine con un orgiástico desenfreno sexual; aquí no se da el caso, pero sí los besos de vasallaje al diablo en sus partes más indecentes y las posesiones que sufrieron. Todas las brujas europeas las califican de harto desagradables y bañadas en un

Bowser, F.B., El esclavo africano en el Perú colonial (1524-1650). México 1977, pág. 295. AHN, Inquisición, libro 345, fols. 82-82v.

Ortiz, F., Historia de una pelea cubana entre los demonios. La Habana 1975, págs. 78 y SS.

10 Para un estudio profundo, con numerosa bibliografía, sobre los aquelarres, cfr., BLÁZQUEZ

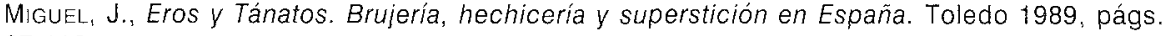
$37-112$ 
semen helado, pero aquí este detalle tan sólo se encuentra en la negra Catalina de Otavio, siendo tan frío que la tuvo enferma durante tres meses. El resto de las negras copuladoras, como Dorotea de Palma o Rafaela de Nava, lo sintieron caliente e incluso para alguna, como Ana Juárez, fue como agua hirviendo. Todas ellas fueron sentenciadas a confiscación de bienes - que no alcanzo a ver cuáles podrian ser, considerando su posición social- y la mayoría añadió a lo anterior cien o doscientos azotes y destierro, saliendo en el auto de fe celebrado en la iglesia mayor de Cartagena el 26 de marzo de $1634^{11}$.

Que esto no fue más que una mascarada organizada por crédulos inquisidores, que confundian realidades con fantasías, se echa de ver en que todas, absolutamente todas las encausadas dicen lo mismo con idénticas palabras, existiendo diferencias nimias; lo que prueba que no hacian más que responder a una especie de cuestionario preparado de antemano por el Santo Oficio.

En el mismo auto salió la negra criolla Teodora de Saucedo, bruja de la Habana, una de tantas de las que se quejaba por esas fechas fray Alonso Enríquez, obispo de esa ciudad ${ }^{12}$, que es la que mejor describió los actos a los que decía asistir. Hacía cinco años que fue llevada a medianoche al corral de una casa, donde se encontraba un trono rodeado de brujas; sentado en él se hallaba una extraña figura vestida con largos ropajes, hediondo de azufre, que la ordenó hacer una cruz en el suelo y luego borrarla con el trasero, con lo cual renegó de la Iglesia y después fue foseida sodomíticamente. El poder que a cambio le fue concedido consistió en ser capaz de confeccionar unos polvos maléficos para perjudicar a las personas o animales que desease y a continuar con ayuntamientos carnales diabólicos ${ }^{13}$.

Mestiza era Fabiana Sánchez, vecina de Celendín, en la provincia de Cajamarca. Los mestizos son el elemento étnico cuantitativo, después de los Indios, en América ${ }^{14}$. Eran muchos los abandonados por el padre y su vida gravitaba alrededor de la madre, pero su obsesión era ser españoles, vestirse y parecerse a ellos ${ }^{15}$ y ese era el caso de esta supuesta bruja, lo mismo que su marido, el también mestizo Juan de Oriarce. Fa-

\footnotetext{
AHN, Inquisición, libro 1020 , fols. 315 y ss.

Ortiz, F., Historia, pág. 409

AHN, Inquisición, libro 1020, fols. 316v.-218.

Israel, J.l., Razas, pág. 68; Pérez de barradas, J., Los mestizos en América... Madrid

Jiménez Moreno, W., «El mestizaje y la transculturación en Mexiamérica», El mestizaje en la Historia de Ibero-América. México 1961, págs. 78-85.
} 1976. 
biana era una extraña mujer, con unas indudables dotes para erigirse en cabecilla y unas raras facultades para fascinar a sus seguidores, con los que en determinadas fechas se dirigía a una cueva, donde agotados por la larga caminata se dormían. A medianoche eran despertados por la bruja y dándoles de comer ciertas hierbas comenzaban a bailar frenéticamente, cantando: «Padre mío, señor mío, tu eres mi faborecedor, tu siempre atiendes a mis ruegos, permite que todo sea faborable y atiende a los ruegos que de los que buscan necesitados". Roncas voces, salidas de los más profundos recovecos del antro, les respondían y bebiendo un cocimiento de gigantón se introducían en la boca harina de maíz, rociando la cueva con soplos, tras lo cual se les aparecía un ser monstruoso ${ }^{16}$, escena ésta en la que conjuga perfectamente la fantasía provocada por la fuerza de las drogas, el baile y la sugestión o magnetismo personal de una mujer, todo lo cual les debió de producir muy pocas preocupaciones a los inquisidores peruanos.

De mayor envergadura fue el caso de Paula de Eguíluz, a quien un mal día se le apareció el diablo en forma de mujer y después bajo guisa de galán, teniendo el consabido acceso carnal con él, tras lo que le llevó a un aquelarre muy cerca de La Habana. Declaró haber asesinado y chupado a un niño, por lo que fue condenada a servir a los pobres en un hospital. Esto ocurrió en 1623, pero en 1630 de nuevo se tiene que enfrentar a los inquisidores, pues se dedicaba a formar brujas entre todas sus míseras vecinas y amigas. Un diablo, llamado Mantelillos, le había enseñado la ciencia de hacer extrañas curaciones y también la manera exacta de desenterrar cadáveres y devorarlos en sus fantásticos aquelarres. Esta vez se le dieron doscientos azotes y fue condenada a llevar hábito y cárcel perpetua ${ }^{1 ?}$.

Si la sexualidad en estos casos siempre se encuentra latente, ésta explota en el del doctor mexicano José de la Peña y Flores, enamorado hasta la médula de una linda y casquivana jovencita. Desesperado al verse abandonado al cabo de un año de intensas relaciones y enloquecido por la ausencia comienza a hacer satánicas invocaciones; primero se rocía con la diabólica hierba conocida con el nombre de «calamtha», sin que nada suceda; después utiliza palma bendita, cabellos y cera de agnus y de altar para confeccionar figuras, con el mismo resultado. Finalmente, se entrega al diablo en cuerpo y alma, llegando a componer versos en su honor, en presencia de la ingrata arpía, que no hacía sino mofarse de

AHN, Inquisición, leg. 3725/28.

7 Ibidem, libro 1013, fols. 161-166. 
él. Aburrido y asustado, acaba presentándose ante los inquisidores y declarando sus debilidades y delitos ${ }^{18}$ y es que se le debió de olvidar lo más importante, cual es escribir una cédula como la que redactó el cuzqueño Leonardo Álvarez de Valdés: «Digo Yo, Fulano, que dare y entregare mi alma a los demonios luego que salga deste mi cuerpo y que hago y hare pacto explícito con qualquiera que se me aparezca y lo firmo de mi nombre». Claro que también se libró de que, como a Leonardo, tan sólo se le aparecieran los inquisidores y le condenaran a una buena tanda de azotes y a servir varios años en un presidio militar ${ }^{19}$ en el que afortunadamente no estaba un milite de ilustre prosapia, don Joaquín Primo de Ribera, teniente coronel de artillería y comandante general de las islas de Arobo y Fernando Poo, quien públicamente comentaba que el diablo se le aparecía tres veces diarias y le tenía informado de cuanto sucedía en la colonia del Santísimo Sacramento y a tanto llegaba su amistad diabólica que se negó a erigir una capilla para sus soldados, sin que la Inquisición le concediese la menor importancia ${ }^{20}$.

Más curiosos son los supuestos casos de posesión diabólica que se dieron en América, sobre todo a finales del siglo XVII y hay que recordar que son casi contemporáneos a los procesos brujeriles de Salem, que sin ser nada excepcionales - de hecho fueron infinitamente menos trascendentes que la mayoría de los procesos europeos-, pero acaso debido a la escasez de hitos históricos transcendentales, como país joven que Norteamérica es, han merecido una abundancia muy meritoria de estu$\operatorname{dios}^{21}$.

En 1681 el convento de monjas de Trujillo estaba asistido por confesores franciscanos, quienes debieron calentar las monjiles cabezas con ideas infernales. Lo cierto es que tan pronto una hermana se creyó poseída, el resto de la comunidad, progresivamente, siguió sus pasos. Las contorsiones, los latinajos y los revuelcos eran dignos de verse y a ellos asistía media ciudad, como si de un espectáculo teatral se tratase. Acudió un especialista jesuita y entregó una bolsa conteniendo estiércol de caballo a la monja más poseída para que se lo colgase del cuello, asegurándola que era milagrosa reliquia, con lo que al instante se curó. En definitiva, la Inquisición ordenó que los franciscanos abandonasen el con-

18 Ibidem, leg. 2280.

lbidem, libro 1032, fols. 240-241

Ibidem, leg. 2214/19.

21 Cfr. LEVIN, D., What happened in Salem? New York 1952; JACKSON, SH., The Witcheraft of Salem Village. New York 1956; Hansen, CH., Sorcellerie and Salem. París 1971. 
vento y al punto las posesiones desaparecieron como por ensalmo, y nunca mejor empleada la palabra ${ }^{22}$.

Dos cosas conviene matizar en este caso. La primera es que cuando una mujer, monja o no, se considera poseída, lo normal es que se desate una ola de posesiones en todas las que están a su alrededor, como se vio en el caso de las madrileñas monjas de San Plácido o en las de los conventos de Corella y Antequera ${ }^{23}$.

La segunda anotación es lo referente al estiércol de caballo, que no se crea privativo de incultos personajes, pues conocido es que en los últimos momentos de la vida del cardenal Richelieu, cuando las medicinas habían dejado de servir, le fue suministrado una panacea consistente en cuatro onzas de cagajones macerados en un cuartillo de vino blanco, y con excrementos de caballo en la boca murió el que acaso fuese el hombre más poderoso de su época ${ }^{24}$.

Un caso muy interesante se dio en 1691, siendo su protagonista Juana de los Reyes, vecina de Querétaro, ciudad tranquila hasta que se establecieron los padres de la Propaganda Fidei. De momento obligaron a las fervientes y crédulas creyentes que permaneciesen casi todo el día en la iglesia dándolas incluso de comer y adoctrinándolas hasta el extremo que sus maridos se quejaron que estaban medio aleladas. En este ambiente de exarcebada religiosidad se detiene a una coyota, es decir, hija de barcino y mulata ${ }^{25}$, la "Chupaterrones», bruja redomada, lo que produce un cierto pánico en la ciudad.

En estos precisos momentos, Juana de los Reyes, hija de hidalgo, de diecisiete años de edad, cae enferma y al ver los extraños síntomas que presenta se le considera poseída y comienzan los exorcismos. Como de costumbre, a la vista del espectáculo otras dos mujeres siguen sus pasos y a partir de aquí las novenas, rosarios, procesiones, cilicios y flagelaciones se apoderan de Querétaro y como no podía ser menos, siete monjas presentan los mismos síntomas.

\footnotetext{
22 MEDINA, J.T., Historia del Tribunal de la Inquisición de Lima (1569-1820). Santiago de Chile 1956, II, págs. 185-186.

23 BLÁzQuez Miguel, J., Madrid. Judios, herejes y brujas. El Tribunal de Corte (1650-1820). Toledo 1990, págs. 109-112; BıÁzQuez Miguel, J., Eros y Tánatos, págs. 107-110

24 XuXley, A., Los demonios de Loudun. Barcelona 1980, pág. 269

25 HeRnández SánChez-BARBA, M., "La sociedad colonial criolla», vol. XXXII de la Historia de España, dirigida por Jover Zamora, J.M. Madrid 1988, pág. 218. En dicha página puede conocerse los distintos términos utilizados para designar las diferentes mezclas raciales americanas.
} 
Juana, la protagonista, estaba cada vez peor: arrojaba por la boca lana empapada de solimán crudo, cabellos e incluso alfileres, llegando a durar los exorcismos hasta ocho horas. Por sus partes femeninas expulsaba diversos objetos y, finalmente, iparió una criatura!, que se considera infernal, pero que es bien natural.

Naturalmente, alguien ha de ser culpable, y los religiosos no dudan en acusar a la pobre "Chupaterrones", que es detenida y casi linchada por la enloquecida multitud, que no le perdona que haya traído al diablo a la pacífica Querétaro. La Inquisición interviene y dejando de lado a esa infeliz, interroga a Juana que estaba medio obnubilada de tanto exorcismo y parto, y tras breve proceso fue condenada a un año de reclusión en un convento, para que su alma se pacificase y su cuerpo se recuperase ${ }^{26}$.

\section{DROGAS Y BRUJERIA}

La relación brujas con ungüentos (drogas) es una constante desde que se apreció una interrelación entre sus supuestos vuelos y el sopor que sufrían. Uno de los primeros que se dieron cuenta de esto fue el doctor Andrés Laguna y más recientemente ha sido puesto de manifiesto por M.J. Harner, que ha estudiado a fondo los ungüentos que utilizaban, llegando a la conclusión de que si no todos, al menos la mayoría contienen atropina, poderoso alcaloide. El bastón o escoba sobre el que muchas brujas decian volar servía para aplicar las plantas que lo contenían a las sensibles membranas vaginales y que ese alcaloide producía un profundo letargo a quienes de ellas se valían, al modo de nuestras actuales drogas - «viajes» se denominan también los paraísos artificiales en los que los drogadictos se sumergen hoy día- es algo en lo que están de acuerdo quienes abordan el tema con rigor y seriedad ${ }^{27}$.

El peyotl para los indios era algo religioso, mítico, que lo mismo proporcionaba sensación de invulnerabilidad que servía para descubrir cosas lejanas y ocultas $^{28}$. Su principal alcaloide es la mezcalina, que produce un síndrome disociativo propio de los esquizofrénicos, originando visiones y alucinaciones cromáticas ${ }^{29}$.

\footnotetext{
25 Alberro, S., Inquisición y sociedad en México, 1571-1700. México 1988, págs. 508-525. El proceso de Francisca Mexia, otra de las principales partícipes de las posesiones de Querétaro, AHN, Inquisición, leg. 1733 (2)/18.

27 Blázouez Miguel, J., Eros y Tánatos, op. cit. págs. 23-24.

28 Michaux, H., El infinito turbulento. México 1979, págs. 101-102.

29 Brau, J.L., Historia de las drogas. Barcelona 1970, págs. 207-209. El estudio más inte-
} 
Ya los primeros religiosos que trataron con esta droga advirtieron que producía efectos alucinógenos, aunque estas propiedades se atribuían a efectos del demonio, no a la hierba en $\mathrm{si}^{30}$, indicando a la vez que no sólo era ésta la planta utilizada, sino otras muchas más, con efectos similares ${ }^{31}$.

Desde los primeros momentos la Inquisición promulgó edictos de fe contra quienes consumían estas drogas ${ }^{32}$, culminando en el de $1616^{33}$, sin que se alcanzase resultado alguno.

Otra hierba muy empleada era la conocida como del «Paraguay», utilizada sobre todo en prácticas curanderiles, y que causó la muerte del inquisidor Martín de Cortázar y Azcárate, que la tomaba sin permiso del médico ${ }^{34}$.

Hierba maldita fue en los primeros años el mate, denunciándose a la Inquisición el gran consumo que hacían de ella los indios en el Paraguay, acuciados por el demonio y las supersticiones, pero pasado el tiempo la otrora hierba diabólica se transformó en la principal riqueza de la república jusuítica guaraní, convirtiéndose casi en un don de Dios; ya no producía pereza y abulia, sino fuerza y estímulo para el trabajo ${ }^{35}$.

La droga que más aparece en los anales inquisitoriales, o al menos sus efectos se encuentran más detallados, es la coca. Ya los primeros tratadistas consideraron que era notoria su capacidad para calmar el hambre y la sed, advirtiendo que muchos españoles se habían enriquecido con su cultivo ${ }^{36}$ y que el mayor negocio de Cuzco era el de su comercio, la cual se traía principalmente del valle de Toayma ${ }^{37}$.

En los Andes se tomaba coca por lo menos 4.000 años a. de J.C. ${ }^{38}$; su hoja es estimulante, poseyendo catorce alcaloides y siendo sus efectos

resante sobre el peyotl, continúa siendo, a pesar del tiempo transcurrido, el de RouHIERS, A., La plante qui fait émervéilles: le peyotl. París 1926.

30 CÁRdenas, J. DE, Problemas y secretos maravillosos de las Indias. México 1591, libro I, cap. I, pág. 4.

${ }_{31}$ Ibidem, libro III, cap. último, págs. 234 y ss.

32 Alberro, S., Inquisición, op. cit, pág. 75.

3. Guerra, F., «La ciencia precolombina y la Inquisición», Arbor, CXXIV 1986, 484-485, págs. 57-64.

${ }_{34}$ Medina, J.T., La Inquisición en Cartagena de Indias. Bogotá (s.a.), pág. 120.

35 Tormo SANZ, L., "La Inquisición y los indios del Paraguay", en La Inquisición española, nueva visión, nuevos horizontes. Director, J. Pérez Villanueva. Madrid 1980, págs. 479-501.

36 Cárdenas, J. de, Problemas, libro II, cap. XIII, pág. 133.

37 López de Velasco, J., Geografía General de las Indias. Madrid 1894, págs. 244-245.

38 Uso tradicional de la coca y narcotráfico, en La coca... tradición, rito, identidad. México 1989, págs. 17-33. 
de alguna manera similares a los del café o té. Por su acción farmacológica y sus implicaciones sociales, no cabe duda que es una planta fascinante ${ }^{39}$.

Al margen de la coca, y para tener exclusivamente revelaciones, la Inquisición peruana hubo de enfrentarse a quienes consumian achuma y chamico $^{40}$.

Antes de continuar, es de advertir que es un error farmacológico considerar que todas las drogas que se consumían eran activas, pues al parecer la mayoría no lo son, siendo sus pretendidas virtudes meras supersticiones y sugestiones ${ }^{41}$.

Los conjuros empleados son muy curiosos y por lo general bastante extensos, en los cuales se mezclan palabras en quechua y en castellano ${ }^{42}$.

\section{EL TRASPASO A INDIAS DE LOS SECULARES MIEDOS HISPÁNICOS}

El momento álgido de la persecución contra las supersticiones en los Tribunales americanos es durante los primeros cuarenta años del siglo XVII, exactamente igual que en los Tribunales españoles ${ }^{43}$, lo cual es difícil que se deba a la casualidad, entendiendo más bien que fue un momento en que los criptojudios no eran abundantes, la lucha antiluterana, como antes hemos indicado, había decaído profundamente y los demás delitos no eran apenas significativos, por lo que la Inquisición hubo de dirigir sus miras a hechiceras y demás calaña, de las cuales jamás faltaba una buena remesa con las que llenar las cárceles inquisitoriales. Así, por ejemplo, el comisario de Guatemala escribe sobre la abundancia de hechiceras en la ciudad «... que si todas hubiese de castigar V.S. no tendría cárceles donde ponerlas... ${ }^{44}$, el obispo de Panamá indica que toda la provincia estaba infectada de hechiceras y hechicerías ${ }^{45}$ y las autoridades cartageneras informan que en la ciudad, acaso por la amalgama de las artes ocultas indias, negras y españolas, las hechicerías pululan por todas partes, y

\footnotetext{
39 "Cosmovisión andina y uso de la coca». Coordinador J. Ossio Acuña, en La coca... tradición, págs. 231-385.

40 AHN, Inquisición, libro 1040, fols. 85

4 GueRrA, F., "Los errores de interpietación histórica en la transculturación de la Materia Médica Americana", Asclepio, 26, 1974, págs. 385-412.

42 La transcripción de los más interesantes puede verse en BlázQUez MIGUEL, J., La Inquisición en América (1569-1820). Port-au-Prince 1994

43 BlázQuez Miguel, J., Eros y Tánatos, op. cit., véase gráfico de la pág. 323.

44 Archivo General de la Nación (México, D.F.), tomo 497/15.

45 Osonio, A., Judaísmo e Inquisición en Panamá Colonial. Panamá 1980, pág. 118.
} 
son una plaga en las minas de Zaragoza ${ }^{46}$. En Perú «las mas de las causas que se ofrecen en esta Inquisición son de casados dos y tres vezes y de superstiziones y embustes de hechiçerias... y las personas que cometen estos delitos son provissimos y suelen residir muchos de ellos a distancia de esta çiudad... ${ }^{47}$. Baste saber que en esta misma inquisición, tras leerse el edicto de fe de 1627 , se recibieron tantas denuncias de "hechizerias y supersticiones de que esta çiudad esta muy lastimada en todo genero de / estas / gentes", de las que únicamente se procesaron unas cuantas ${ }^{48}$, por ser materialmente imposible de atender por los inquisidores que las consideraban «embustes y embelecos de mugeres para sacar dineros y no inducen sospecha de heregia ni pacto con el Demonio» ${ }^{49}$.

Redadas de estas mujeres siempre había ocasión de efectuar, como la de Celaya. En efecto, el ambiente hechiceril estaba a flor de piel desde el mismo momento de la creación de la ciudad de 1570 por estancieros, casi todos de origen vasco. Su mismo nombre, Celaya deriva de la palabra vasca Salaia, tierra llana en vascuence. En 1614 era comisario Pedro Núnez de la Rosa, hombre rico que tenía excesivas ambiciones y necesitaba hacer méritos ante los ojos inquisitoriales y para ello recurrió a una antigua acusación de 1608 de temas hechiceriles. Más de una veintena de personas testificaron ante él y poco después la Inquisición envió a Diego Muñoz, que mandó publicar un edicto general de fe; al día siguiente fueron 115 las personas, la mayoría mujeres, las que se presentaron a testificar. Nada tuvo la menor importancia para los inquisidores cuando examinaron los casos y se limitaron a reprender a 21 mujeres y un hombre $^{50}$.

Observando el caso de Celaya podemos preguntarnos si acaso no existe una relación con algunos movimientos brujeriles similares en la Península y contemporáneos. Lo primero que se nos viene en mente es que Celaya era habitado por vascos y en 1609 se inició la persecución brujeril en Zugarramurdi, la última, pero la más famosa y cruenta de cuantas Ilevó a cabo la Inquisición española contra estas servidoras del Diablo. Esto nos hace sospechar si no habrían llegado los ecos de esta tragedia, por medio de familiares o paisanos vascos, hasta los vecinos de Celaya

\footnotetext{
LEA. H.C., The Inquisition in the Spanish Dependencies... London 1908, págs. 461-463. AHN, inquisición, libro 1045, fols. 293.

Ibidem, libro 1039, fols. 349-350.

49 Ibidem, libro 1031, fols. 338.

so Alberro, S., Inquisición, págs. 283-323; Ibidem, "Hechicería y proceso de cambio social:
} Celaya 1614", Revista de Dialectología y Tradiciones Populares, XXX, 1974, 3/4, págs. 327-385. 
y el asunto fue aprovechado por Núñez de la Rosa. También por esas mismas fechas se dio otra persecución en Jarque (Zaragoza), y en pleno apogeo estaba lo que fue base y génesis de todos estos procesos, la persecución antibrujeril en los Pirineos franceses dirigida por Pierre de Landre. En los años de 1611-1612 hubo epidemias brujeriles en Fuenterrabía y la zona norte de Burgos y las matanzas en tierras catalanas - llevadas a cabo por las autoridades civiles, jamas por la Inquisición, quede esto muy claro- alcanzaron algunos centenares ${ }^{51}$.

Eran años recios en la Península y, por ende, no sería extraño que sus secuelas se dejasen sentir en Indias, aunque afortunadamente en ellas no fue sino un débil reflejo de algo que algunos quisieron convertir en palpable tragedia y que la Inquisición no dejó que pasase de un mero sainete.

Y así continuamente por doquier, pues, por ejemplo, apenas una decena de años después, entre 1620 y 1623, una ola de acusaciones se extendió por Guadalajara en la que se vieron involucradas centenares de personas y cien años después le toca el turno a Coahuila, es decir, la historia de las acusaciones se repite una y otra vez y todo se reduce siempe a lo mismo: detenciones de mujeres con fama de hechiceras que al final son dejadas en libertad, la mayoría de las veces sin castigo alguno ${ }^{52}$.

Debieron ser miles, como en la Península, las mujeres que en cualquier época pululaban por los pueblos y ciudades americanas sacando el dinero a incautos a base de conjuros y pócimas y el número de procesados no es apenas más que la punta del iceberg. Los conjuros son muy parecidos a los hispanos, como iremos viendo, basados en las mismas «mágicas" premisas y personajes, y sus autores o eran españolas o estaban totalmente impregnadas de su cultura.

La hechicería americana, exactamente igual que la española, está orientada a lograr la riqueza y, sobre todo, el amor. Otra historia es lo de la salud, ligada al curanderismo, del que luego hablaremos.

Para lo de la riqueza lo más común era el poseer algo que proporcionase suerte en los juegos de azar - de los zahoríes, capaces de hallar tesoros ocultos en las huacas de las que hablaremos en su momento-

Para todo este asunto, cfr. BlázQuez Miguel, J., Eros y Tánatos, op. cit., págs. 65-82.

CALvo, T., "Calor de hogar: las familias del siglo XvIl en Guadalajara», Sexualidad y matrimonio en la América-Hispánica. Siglos XVI-XVIII. Coordinadora, A. Lavrin. México 1991, págs. 309-338; AHN, Inquisición, leg. 2282. 
y una de las argucias más empleadas fue utilizar una hostia consagrada. El suponer que llevando consigo una hostia, es decir, el cuerpo de Jesús, su poseedor no sufriría daño alguno, fue una creencia muy extendida en los siglos XVI y XVII, aunque para el Santo Oficio esto no era considerado más que como una profanación. También se empleó para encontrar tesoros encantados ${ }^{53}$.

Un tal Juan de Zubiate extrajo del sagrario dos formas consagradas y se hizo una herida en el brazo derecho, introduciéndose una de ellas, todo para tener suerte en el juego de los albures, lo que le valió una ligera sentencia ${ }^{54}$. Poco más o menos por esas fechas, muy lejos de allí, en Nancy (Francia), estaban detenidos cuatro judios. Uno de ellos, con ciertos conocimientos mágicos, consiguió una hostia y tras varios conjuros se introdujo un pedazo en una herida que a tal fin se había provocado. El asunto se descubrió y dos judíos fueron ahorcados y sus cuerpos quemados, mientras que los otros dos restantes fueron condenados a galeras a perpetuidad ${ }^{55}$.

Relacionado de alguna manera con la riqueza está el hallar objetos valiosos perdidos o robados. Esto ya era una tradición entre los aztecas, entre otros, y para lograrlo, el hechicero arrojaba unos granos de maíz en un lebrillo y allí decía verlos ${ }^{56}$. Las hechiceras perseguidas por la Inquisición utilizaban algo similar, que veremos más detenidamente, aunque el uso de este sistema era fundamentalmente aplicado a saber de enamorados.

Lo que sí era muy empleado era el cedazo, para lo cual se tomaban unas tijeras y se clavaban en el aro del cedazo, asiendo en la mano el anillo de una parte y con la otra formando una especie de cruz y recitando ciertos conjuros, que los había de todo tipo ${ }^{57}$, sistema empleado entre centenares de hechiceras por Beatriz de Trejo, quien nos informa que en Potosí había verdadera afición a él, allá por los años treinta del siglo XVII ${ }^{58}$. Uno de los conjuros más conocidos decía: «Por San Pedro y San Pablo y el Apostol Santiago y el glorioso San Andres que me digas esto lo que

53 Blázquez Miguel, J., Castilla-La Mancha. Magia, Superstición y Leyenda. León 1991, págs. 137-138; Ibidem: Eros y Tánatos, págs. 160-163.

54 AHN, Inquisición, leg. 1732/69.

55 BlázQuez Miguel, J., Eros y Tánatos, op. cit., pág. 163.

36 Toribio de Benavente, Historia de los Indios de la Nueva España. Introducción y notas de G. Bellini. Madrid 1988, pág. 179.

57 BlázQuez Miguel, J., La hechicería en la Región Murciana (Procesos de la Inquisición de Murcia, 1565-1819). Yecla 1984, pág. 89.

s8 AHN, Inquisición, libro 1030 , fols. 354-356v. 
es» ${ }^{59}$ y estos eran los rituales utilizados por el mulato Sebastián Antón de Murcia, por citar algún caso concreto ${ }^{60}$.

A lo que verdaderamente dedicaban sus afanes las hechiceras era a los asuntos del amor. Por lo general una hechicera no era más que una pobre mujer, de clase baja, dedicada a alegrar la vida de los hombres, embolsándose de paso unos cuantos pesos. Naturalmente, para que no les faltase clientes, si no eran todo lo atractivas que hubieran querido ser, necesitaban recurrir a conjuros que facilitaran el acercamiento. Estos conjuros les eran enseñados por colegas, que a su vez los habían aprendido de otras y así sucesivamente. La mayoría de los conjuros o medios para realizar sus deseos no es que sean ingenuos, es que son verdaderamente pueriles y hoy día hacen reír a un niño a punto de tomar la primera comunión, pero durante siglos hicieron anhelar, soñar, desear y creer a decenas de miles de mujeres, por lo cual no pocas de ellas tuvieron algún tropiezo, benigno la mayoría de las veces, con la Inquisición.

La supuesta potencia mágica de los huesos de los difuntos ha sido una constante en casi todas las épocas de la humanidad y no pocas hechiceras se dedicaban a cogerlos y machacarlos para confeccionar polvos que arrojados sobre la persona amada, o bien en la puerta de su casa, adobados con algún que otro conjuro, se suponía que obraban milagros. El caso más famoso de un «especialista» fue el de Ignacio Rodríguez, en el Madrid de finales del siglo XVIII, que incluso fue dibujado por Goya ${ }^{61}$.

En América estos casos no son tan frecuentes, al parecer, como en España ${ }^{62}$, pero de vez en cuando aparece alguna que otra hechicera que hurgando en las huacas sacaba huesos destinados a fines amorosos, como Catalina Baena, vecina de Potosí, que fue desterrada por sus aficiones pseudoarqueológicas ${ }^{63}$.

59 BlázQuez Miguel, J., Ciudad Real y la Inquisición (1483-1820). Ciudad Real 1986, pág. 67; otros conjuros en Blázquez Miguel, J., Castilla-La Mancha. Magia,pág. 114.

B० AHN, inquisición, libro 1067, fols. 430v-432.

61 BlázQuez Miguel, J., Madrid. judíos, págs. 121-122. También la magia o brujería india tenía su tradición con respecto a los muertos, como los muy temibles brujos aztecas llamados temanpalitotique, que utilizaban para sus conjuros el brazo amputado del cadáver de una mujer muerta durante el parto. Sepúlveda, M.T., Magia, brujería y supersticiones en México. México 1983 , págs. $47-48$.

62 BlázQuez Miguel, J., Hechicería y superstición en Castilla-La Mancha.Toledo 1985, págs. 44-46; Ibidem: Eros y Tánatos, op. cit., pág. 171; Ibidem, Castilla-La Mancha. Magia, págs. 272 273.

63 AHN, Inquisición, libro 1030, fols. 359v-362v. 
Hay una buena muestra de mulatas que de los lances amorosos hacían su forma de vida que eran vistas con ojos comprensivos por los inquisidores. Los mulatos eran muy numerosos en el momento álgido de la persecución hechiceril: unos 144.000 en México, América Central y Antillas y unos 95.000 en Suramérica ${ }^{64}$. Raza de hombres y mujeres astutos y rapaces, de costumbres poco católicas y no teniendo ninguna consideración para el sexto Mandamiento ${ }^{65}$.

Hechicera prostituta era la mulata Ana de Almansa, de Panamá, especialista sobre todo en echar las habas, para lo cual tomaba dos y las introducía en su boca. Una simbolizada al varón y la otra a la hembra. Seguidamente, apartaba dos montones de quince habas cada uno, con igual simbología que los anteriores, y una porción de diferentes objetos pequeños, tales como oro, plata, cera, alumbre, carbón, sal, barro, lienzo, etc. Conjurándolos y mezclándolos, sabía lo que depararía el futuro; por ejemplo, si salía barro quería decir casa, hogar; si oro, dinero que traería el amante, etc. ${ }^{66}$.

La utilización de las habas para este tipo de conjuros es acaso lo que con mayor frecuencia empleaban estas mujeres, no habiendo apenas ninguna que se preciase de hechicera que no recurriese a ellas ${ }^{67}$.

Los conjuros son interminables y poco diferentes de los recitados en la Península ${ }^{68}$. Y es que las habas ya eran consideradas como algo especial desde al merros la época de los egipcios, que las tenían por funestas, en las que se encontraban las almas de los difuntos, tradición que pasó a los pitagóricos quienes tuvieron prohibido su consumo. En el mundo romano se relacionaron con los cultos funerarios y de ahí derivó su relación con la magia, de todo lo cual ya hemos escrito detenidamente en trabajos anteriores ${ }^{69}$.

Esta suerte de las habas, importada por hechiceras españolas, paulatinamente fue sustituyendo a la adivinación por el maíz seco cuyo dios,

\footnotetext{
64 LuCEna Salmoral, M., "La estructura uniforme de lberoamérica como región", Historia de Iberoamérica. Madrid 1990, II, págs. 323-419.

55 AzARA, F. de, Descripción general del Paraguay. Edición, introducción y notas de A. Galera Gómez. Madrid 1990, pág. 161.

66 AHN, Inquisición, libro 1030, fols. 309-313.

67 BlázQuez Miguel, J., Brujeria. Manual práctico. Madrid 1988

68 AHN. Inquisición, libro 1065, fols. 21v-22v.

69 Blázquez Mıguel, J., Eros y Tánatos, op. cit., págs. 274-275; Ibrdem, Castilla-La Mancha. Magia, págs. 262-268; Ibidem, Brujeria, pág. 50; Ibidem, Hechicería y superstición, pág. 141; Ibidem, Hechicería en la Región Murciana, págs. 101-104.
} 
Cinteolt, era invocado para controlar y dirigir los asuntos del amor, siendo, además, protector y facilitador del adulterio ${ }^{70}$.

Actualmente las cartas, especialmente el tarot, han desbancado a las habas para adivinar el futuro, pero al menos desde el siglo XVI hechiceras había que las utilizaban, valiéndose de una baraja normal, con un específico simbolismo que en casi todas era el mismo ${ }^{71}$.

No muy utilizada en España era la suerte del Rosario, que nuestra conocida Ana de Almansa recitaba así: "Conjurote quentas y cordon con la madre de Dios de los Ángeles del coro del cielo, si Fulano esta con alguna muger, dimelo y sino desengañame y anda alrededor en el nombre del Padre y del Hijo y del Spiritu Sancto" ${ }^{72}$ y lo mismo puede decirse de la suerte de San Nicolás, cuyo texto desconozco ${ }^{73}$, santo éste relacionado de alguna manera con la fertilidad ${ }^{74}$ y que se recitaba ante unas velas encendidas y con ayuda de un cubilete.

La sangre menstrual, lo mismo que el semen varonil, era sumamente utilizada para conjuros amatorios por razones obvias. Rara es la hechicera que en alguna ocasión no los empleó ${ }^{75}$, como Juliana Lago, anciana mexicana de más de sesenta años que comía corazones de víbora para proporcionarse fuerza y mezclaba sangre menstrual con conservas que daba de comer a sus amantes sin que éstos lo adviertiesen, naturalmente.

$Y$ es verdaderamente curioso cómo ha persistido esta asquerosa costumbre hasta nuestros días en muchos pueblos hispanoamericanos, habiencio sido profusamente estudiada por múltiples autores que han dado fe de ella, siendo especialmente empleada en Guatemala, donde en no pocos lugares las esposas mezclan su sangre menstrual con fríjoles que ofrecen sumisa y candorosamente a sus esquivos esposos ${ }^{76}$.

Quezada, N., Amor y magia amorosa entre los aztecas. México 1984, págs. 77 y 81

AHN, Inquisición, libro 1031, fols. 527-531.

AHN, Inquisición, libro 1030, fols. 373-377v.

Ibidem, libro 1030, fols. 354.356v.

Garcia Atienza, J., Santoral diabólico. Barcelona 1988, págs. 71-72.

BLAZQUeZ MIguel, J., Huete y su tierra; un enclave inquisitorial conquense. Huete 1987, pág. 94; Herejía y heterodoxia en Talavera y su antigua tierra (Procesos de la Inquisición, 1478820). Talavera de la Reina 1989, pág. 193.

AHN, Inquisición, libro 1067, tols. 320-325v.; BEHAR, R., «Brujería sexual, colonialismo y poderes femeninos: opiniones del Santo Oficio de la Inquisición en México", Sexualidad, págs. 197-226; PAUL, L., "The Mastery of Work and the Mystery of Sex in a Guatemalan Village", Woman, Culture and Society. Ed. M.Z. Rosado and L. Lamphere. Stanford 1974, págs. 281-299; BEHAR, R., "Sex and Sin, Witchcraft and the Devil in Late-Colonial Mexico", American Ethnologist, $14,1,1987$, págs. 34-54 
En el pueblo de Lambayaque (Perú), vivía en 1770 María de Jesús Cornejo, alias La Jabonera, poseedora de unos polvos amarillos que arrojaba sobre los hombres para despertarles volcánicas pasiones que ella aprovechaba. Mujer de pésima fama, acusada de ocasionar maleficios que otras colegas contrarrestaban, con lo que había montada toda una red de maléficos negocios. Esta curuscante fémina frecuentemente salía a media noche a la orilla del río y allí bailaba y «mochaba» con los indios, lo que para los ojos de los españoles no era sino una parafernalia semejante a un aquelarre. De todas formas su originalidad consistía en que maleficiaba con jabones ${ }^{77}$ a los que tras conjurar debidamente enterraba en las puertas de las casas deseadas. En el inventario que de sus pertenencias se llevó a cabo tras su detención, se hallaron 339 panes de jabón, varios cuadros religiosos, 16 gallinas, un gallo, un taburete, un par de sillas y otras tantas mesitas, un taburete, una mala cama y un baúl con algunas ropillas ${ }^{78}$.

Alguna que otra hechicera se dirigía a San Erasmo, que tanto valía contra los dolores de tripa como para recuperar amantes y de cuya oración se conocen varias versiones ${ }^{79}$.

La oración del Anima Sola fue profusamente empleada, al igual que en España ${ }^{80}$. En la hechiceril Cartagena de los primeros decenios del siglo XVII era famosa. Lorenzana de Acereto que tan pronto mezclaba polvos de una calavera con los de un ara, como recitaba dicha oración para todo lo relacionado con los lances del amor ${ }^{81}$.

El ara estaba sacralizada por su relación con la mesa del altar donde se celebra el sacrificio de la misa y el llevar un fragmento de ella consigo era moneda corriente entre estas mujeres ${ }^{82}$.

El conjuro de la sal era muy empleada por doquier, aunque a tenor de la documentación inquisitorial acaso el lugar donde era más recitado fuera Potosí, ya que la sal es un producto conservador de la materia y

Son rarísimas las hechiceras que utilizan jabones para sus conjuros. Una de ellas fue la madrileña Josefa Carranza y otra la toledana María Magdalena; Cirac Estopanan, S., Los procesos de hechicerias en la Inquisición de Castilla la Nueva (Tribunales de Toledo y Cuenca). Madrid 1942, págs. 154 y 157.

${ }_{78}$ AHN, Inquisición, leg. 2217/8

79 Blázquez Miguel, J., Eros y Tánatos, op. cit., págs. 219, 271 y 288.

so lbidem, págs, 266-288.

81 AHN, Inquisición, libro 1029, fols. 107 y ss. Un buen estudio de este personaje y de la brujería cartagenera, en TEJADO FERNÁNDEZ, M. Aspectos de la vida social en Cartagena de Indias durante el seiscientos. Sevilla 1954, págs. 45-79; PAREDES FERrER, A., «Demonios y brujas en Cartagena de Indias", Lámpara, 115, XIX, 1991, págs. 1-19.

${ }^{82} \mathrm{AHN}$, Inquisición, libro 1029, fols. 5-6v. 
cuyas propiedades son conocidas desde los tiempos más remotos, siendo venerada en la Cábala ${ }^{83}$.

En verdad, esta villa de Potosí merecería un trabajo monográfico. Sus calles eran hervidero humano de las más bajas pasiones; sus míticas riquezas atraían a legiones de aventureros sin escrúpulos; la miseria indígena y su degradación moral eran evidentes en injusto contraste con la riqueza y fastuosidad de la ciudad y de algunos ciudadanos, todo lo cual propiciaba una turbamulta de farsantes dispuestos a embaucar a quienes se pusieran a su alcance y dispusieran de unas monedas y todo ello envuelto en un ambiente de degradación y violencia extremas ${ }^{84}$.

La soga del ahorcado era muy conocida, ya que bien molida servía para preparar unos ungüentos que bebidos por ignorantes e ingratos amantes les dejaba inservibles para eróticos menesteres ${ }^{85}$ y a ella estaban dedicados unos conjurillos que recitados asomándose a una ventana a media noche se creía daban resultados sorprendentes ${ }^{86}$.

En íntima relación con lo anterior está el conjuro del Señor de la Calle, que apenas se diferencia del recitado en España ${ }^{87}$.

Y para amansar a una persona se daban a comer sesos de borrico ${ }^{88}$, aunque por lo general se buscaba un efecto contrario, ya que conocido es el gran poder genésico de ese animal, cuyos sesos han sido muy usados en la confección de brebajes, recomendados incluso por algún que otro religioso ${ }^{89}$, bien conocida esta cualidad por la mexicana Elvira Rodríguez ${ }^{90}$.

El mirar una jícara de agua para saber de personas amádas o ausentes, cual si de brujas sacadas de una tragedia de Shakespeare se tratase, es bien conocido, aunque los indios ya tenían una ancestral tradición al respecto, para lo cual arrojaban unos granos de maíz en el agua; si se hundían en la jícara la respuesta amorosa era favorable. Existían, además,

83 BläzQuez Miguel, J., Brujería, op. cit., págs. 66-67. Para los diversos conjuros, cfr. Ibidem, Eros y Tánatos, págs. 274-275.

${ }^{84}$ CAPOCHE, L., Relación general de la Villa Imperial de Potosi. Edición de L. Hanke. Madrid 1959, pág. 141 (Biblioteca de Autores Españoles, CXXII); Rodríguez. RIvas, R., Médicos y brujos en s: Alo Perú. Cochabamba (Bolivia), 1989, págs. 47 y 104-105

BCizQuez Miguel, J., Eos y Tánatos, op. cit., pág. 255.

36 Cirac Estopanan, S., Los procesos, págs. 122 y 139.

87 Blázquez Miguel, J., Ciudad Real y la Inquisición, op. cit., pág. 69.

8 a Alberro, S., Inquisición, op. cit, pág. 339.

ag Blázquez Miguel, J., San Clemente y la Inquisición de Cuenca. San Clemente 1988, pág. 81.

90. AHN, Inquisición, libro 1064, fols. 83. 
unos hechiceros especializados grandemente en este sistema, llamados atlanteitlaque, para lo cual echaban agua en una jícara pintada de verde oscuro en su interior y miraban su superficie; si reflejaba el rostro de la persona enferma, ésta tenía posibilidades de sanar; si el reflejo no existía o no era claro, probablemente fallecería sin remedio ${ }^{91}$.

Para saber de autores de hurtos utilizaba la jícara de agua doña Isabel de Quiñones, nacida en Talavera de la Reina y viuda de un familiar del Santo Oficio de Antequera. Tomaba dos ascuas del fogón y las colocaba en el suelo, apagándolas después con agua. Sobre las cenizas ponía un cubilete con la boca hacia abajo y dibujaba ciertos círculos acompañados de conjuros. Seguidamente traía un vaso repleto de agua y cierto número de velas ${ }^{92}$ de sebo encendidas que se colocaban junto a él, y su hija, que se supone era virgen, pues si no este conjuro no funciona, afirmaba ver quien era el ladrón ${ }^{93}$ y similar sistema usaba la negra esclava Isabel, que además aseveraba tener un Cristo y un aspa de San Andrés en la boca y que se consideraba zahorí los lunes, miércoles y viernes, no siendo más que una vulgar cuentista ${ }^{94}$.

Este sistema de la hidromancia es algo frecuentemente empleado por brujas y hechiceras de toda Europa, como bien supo Macbeth en Inglaterra y tantos otros no tan famosos como él por toda Europa. España no fue a la zaga y desde la aragonesa Aznara, a principios del siglo XVI, que trazando un círculo e introduciendo en él una redoma de agua, en ella su hija podía ver las personas que deseaba ${ }^{95}$, hasta la vecina de Yecla llamada la "Gila», quien en un lebrillo de agua clara era capaz de ver pasar a las hechiceras rivales como si de contemplar una película se tratase ${ }^{96}$ y esto ya muy entrado el siglo XVIII.

Personaje simpático, al que todas las hechicerillas de tres al cuarto traían como un zascandil y que en fecha temprana hace su aparición en América, es el Diablo Cojuelo, que era imperativamente solicitado por múltiples blancas, mestizas y negras ${ }^{97}$.

\footnotetext{
91 Quezada, N., Amor y magia, pág. 82; Sepúlveda, M.T., Magia, pág. 53.

g2 Civilizaciones indias hubo que hicieron del simbolismo numérico algo mágico. Cfr. FLofES MARTOS, J.A., "Un ritual de magia amorosa mayayucateco, el «kay-nicté», Cuadernos Hispanoamericanos. Los complementarios, 7/8, 1991, págs. 7-19; Para el simbolismo brujeril, cfr. BLÁzQuez Miguel, J., Eros y Tánatos, op. cit., pág. 252.

93 AHN, inquisición, libro 1030, fols. 217-225.

94 Ibidem, fols. 213V.-217.

95 Blazquez Miguel, J., Eros y Tánatos, op. cit., págs. 252-254.

96 Blázquez Miguel, J., Inquisición y brujeria en la Yecla del siglo xvill. Yecla 1984, pág. 110 .

97 Sobre el Diablo Cojuelo, cfr. BlázQuez Miguel, J., Eros y Tánatos, op. cit, págs. 127-128, 274-276, 281-282, 285, 292, 305 y 309; Para procesos inquisitoriales en América: AHN, Inquisición, libro 1030 , fols. 194-1988; Ibidem, fols. 35-36v.
} 
Indudablemente los dos personajes más asiduamente solicitados por las hechieras fueron Santa Marta y Santa Elena. La primera podía ser la Buena o la Mala, aunque en realidad ambas servían para los mismos fines, y variando apenas sus conjuros de los muy conocidos en la Península ${ }^{98}$.

Por lo que respecta a Santa Elena podemos decir otro tanto; madre del emperador Constantino, que halló la Santa Cruz ${ }^{99}$, cuyo conjuro no ofrece ninguna variante en América.

Al margen de estos hechos y conspicuos personajes típicamente hechiceriles, hay otros muchos procesados por diversos actos meramente supersticiosos, que nos hacen entrever un mundo en el que el temor $y$ creencias infantiloides se daban la mano. Por ejemplo, el deseo de hacerse invisible estaba ampliamente difundido y el sistema empleado difería muy poco del de Martín de Hornosa, franciscano de Mechoacán, quien mató un gato negro y le incrustó cuatro habas en los pies y una en cada ojo y oído y otra en la boca, tras lo cual le enterró, no si antes regar la sepultura, por decir algo, muy minuciosamente con óleo santo ${ }^{100} \mathrm{y}$ algo parecido es lo que practicaba el zahorí Diego de la Rosa ${ }^{101}$.

Un dia cualquiera del año 1660 entró en una tienda de la ciudad de México el carmelita Alonso de la Madre de Dios y enseñó a los clientes un extraño juego: tendiéndose uno de ellos en el suelo cuan largo era, otros cuatro le tocaban con sus dedos índices, recitando: «este hombre es muerto llevemosle a enterrar, subele arriba, hechalo al hombro» y ante la sorpresa de los presentes el cuerpo se levantó casi dos varas ${ }^{102}$. Un caso similar tan sólo conozco en las Inquisiciones españolas, ocurrido en el conquense pueblo de Inieste en la mitad del siglo xVII, casi contemporáneo del mexicano ${ }^{103}$.

Mención especial merecen los negros que al margen de cuanto hemos hablado de ellos con respecto a aquelarres y demás, se dedicaban a prácticas supersticiosas ${ }^{104}$, aunque en verdad los inquisidores apenas se ocupaban de ellos y sus dueños por los perjuicios económicos que un proceso les acarreaba eran los primeros interesados en que no fuesen detenidos. Frecuente era entre ellos el llevar un póculo o materia amatoria

\footnotetext{
Blázquez Miguel, J., Eros y Tánatos, op. cit., págs. 284-285 y 287-288.

Ibidem, págs. 268-269; AHN, Inquisición, libro 1065, fols. 21v.-22v.

Ibidem, libro 1064, fols. 94-94v.

Ibidem, libro 1027, fols. 134-136v

Ibidem, libro 1060, fol. 452.

Blázquez Miguel, J., Castilla-La Mancha, Magia, págs. 142-143.

104 Ballesteros Galierois, M., "Negros en la Nueva Granada», Miscelánea de Estudios dedicados a Fernando Ortiz, 2 v. La Habana 1955, págs. 109-123.
} 
para tener más potencia genésica ${ }^{105}$, pero en lo que puede entenderse por magia - blanca o negra- en muy contadas ocasiones se ven involucrados, salvo algún que otro asunto singular, que apenas si merecía algún interés por el Santo Oficio. Y es curioso lo de las sentencias, pues tenemos el caso de una redomada bruja negra, Ana María Vázquez, denunciada como tal por infinidad de testigos sin que los inquisidores se dignaran ni siquiera a interrogarle, pero habiendo robado una negrita cartagenera y falsificando la escritura de esclavitud, fue castigada con doscientos azotes $y$, además, vendida por los propios inquisidores a unos obrajes por espacio de diez años ${ }^{106}$.

No negro, sino pardo, antiguo esclavo y muy relacionado con negros, era Francisco de Rumbos, conocido como «El brujo de Quibor», quien para implorar la lluvia se colocaba en una cruz, como si de Cristo Crucificado se tratase, y una zamba, Ana María, simulaba ser la Virgen. Todos los indios del pueblo de Cubiro acudían en procesión y le besaban la mano, aunque esto no es privativo de este personaje, pues en el conquense pueblo de Torrejoncillo, allá por el año 1548, un tal Juan García Cabronero hizo exactamente el mismo ritual ${ }^{107}$. De todas formas, por lo que al brujo de Quibor se le procesó no fue por irreverencias, sino por unas ceremonias de magia negra que acostumbraba a realizar, consistentes en reunirse con algunos acólitos a medianoche en oscuro aposento. En el centro había una mesa cubierta por un paño - seguramente negroy sobre ella colocaban una gallina y un cabrito sacrificados y sin sal, dos frascos de aguardiente, huevos cocidos y caratos, todo ello presidido por una imagen sacra, y con secretas ceremonias invocaban al diablo ${ }^{108}$.

Por lo que respecta a la salvaguarda de oraciones católicas, muy amenazadas por el sincretismo imperante, continuamente hay órdenes tasativas de prohibir tal o cual oración u objeto, como la que comenzó a circular por el Perú en 1652 y que se decía hallada en el sepulcro de Cristo y con la virtud que su propietario no moriría sin confesión. Con ella andaba una relación acerca de una cabeza que pidió confesión tres días después de cortada. También se puso en guardia - aunque parece que sin motivo, pues no eran conocidas - sobre unas cintas, abanicos y

105 Aguirre Beltrán, C. Medicina y magia. El proceso de aculturación en la estructura coIonial. México 1973, págs. 169-170; IsRael, J.I., Razas, clases sociales y vida política en el México Colonial (1610-1670). México 1980, pág. 81.

106 AHN, Inquisición, libro 1065, fols. 319-320

107 BlázQuez Miguel, J., La Inquisición en Castilla-La Mancha. Córdoba 1986, pág. 173.

108 Veracochea, E.T. de, «Francisco de Rumbos, el brujo de Quibor», Boletín Histórico (Ca racas), 26, 1971, págs. 191-201. 
tejidos llamados tripas de ángeles y corazones y entrañas de apóstoles, con virtudes similares ${ }^{109}$.

A mediados del siglo XVIII la Inquisición intervino seriamente en la ciudad de Panamá, donde comenzaron a cantarse un especial "alabado", y salves, glosas del Ave María y letanías de Cristo Juez, que hicieron furor, manifestándose incluso por las calles. No eran muy ortodoxas, pero, en cambio, estaban cargadas de devoción, por lo que finalmente fueron autorizadas ${ }^{110}$.

Hemos visto que gran número de religiosos estaban involucrados en prácticas supersticiosas, mas no era solamente el bajo clero quien en ello creía -y lo practicaba-, sino que altos personajes de la jerarquía eclesiástica no eran reacios en abandonar por un momento sus oraciones y breviarios y echar mano de supercherías en teoría combatidas por ellos, por si acaso, como fray Juan González de Mendoza en 1611, hasta entonces designado para la silla episcopal de Chiapas, autor de un tratado sobre China, y denunciado porque desde que desembarcó en Cartagena de Indias y llegó a Popayán no hizo sino echar la suerte con unas varillas para adivinar su futuro ${ }^{111}$.

Inquisidor hubo que más caso hacía de curanderos que de médicos, como el mencionado Martín de Cortázar y Azcárate, tomador de pócimas curanderiles que le costaron la muerte ${ }^{112}$. Y también se relacionó la muerte del doctor Andrés Fernández de Hipenza, vicario general del arzobispado de Toledo y obispo electo de Yucatán, con sus amistades hechiceriles, en un Toledo hirviendo de supersticiones y hechicerías a mediados del siglo xvil ${ }^{113}$. Este hombre estaba íntimamente relacionado con una bella hechicera, Ana de la Cruz, abandonada por su marido y necesitada de dineros. Con ella tuvo una hija, pero cuando fue nombrado obispo de Yucatán se desentendió de ambas y según creencia popular fue maleficiado por su amante, comentándose que murió expulsando gusanos por la boca ${ }^{114}$.

A punto estuvo de seguir sus pasos su colega Cabezas Altamirano, obispo de Cuba, relacioriado sentimentalmente con una esclava negra,

109 AHN, Inquisición, 1043, fols. 155-157.

110 lbidem, leg. $2188 / 7$

11. Pinta Llorente, M. de la, La Inquisición española. Madrid 1942, pág. 39.

112 AHN, Inquisicion, libro 1012, fols. 142.

113 Para un estudio del ambiente supersticioso toledano, BLÁzQuez Miguel, J., "Superstición, magia y brujería en Toledo". Actas del/ Congreso del Toledo Mágico y Heterodoxo. Toledo 1989, págs. $25-47$

114 Blázquez Miculi., j. Cas a Mancha. Magia, págs. 263-264; Ibidem; Hechicería y superstición, págs. 140-141. 
Beatriz, que en un momento dado le dio un bebedizo que durante algunos años le tuvieron con falta de memoria, tez amarillenta y como embobado y pasmado, aunque luego parece que se recuperó ${ }^{115}$. Y es que la brujeríahechicería de los negros en Cuba, a nivel inquisitorial, merecería un estudio monográfico sobre todo en el siglo XVIII, pues si en 1774 los españoles eran unos 96.000 , los negros, entre libres y esclavos, alcanzaban los 72.000 , y en 1790 eran unos $120.000^{116}$, la mayoría de ellos creyentes empedernidos en este tipo de prácticas.

La Astrología siempre perseguida por la Iglesia, siempre de alguna manera tolerada, criticada por Don Quijote como algo que inundaba España ${ }^{117}$, no estuvo ausente en América, siendo su más conspicuo representante el irlandés don Guillén de Lampart, que ha sido considerado por algunos nada menos que como un precursor de la independencia mexicana, cuando no fue más que un impostor ambicioso, pero cuya fascinante vida inspiró toda una literatura novelesca. La Inquisición intervino porque fue sospechoso de herejía y durante diecisiete años estuvo en sus cárceles. En realidad lo que hizo fue recurrir a la Astrología para saber el futuro de sus planes políticos y todo eso le costó morir en la hoguera en $1659^{118}$.

Mucho menos importante a nivel histórico, que acaso no a humano, fue Melchor Pérez de Soto, arquitecto y maestro mayor de la obra de la catedral y de las obras reales de la ciudad de México, denunciado y detenido en 1658, aficionado a la Astrología horaria, extraña especialidad hoy casi desaparecida, pero que permitió algunos extraños éxitos descubriendo hurtos e incluso asesinatos ${ }^{119}$ que los inquisidores no supieron explicar. Pues bien, este arquitecto poseía una buena biblioteca de estos temas y era dado a levantar cartas astrales y hacer pronósticos, lo que acaso pudiera haberle reblandecido el cerebro, pues cuando fue detenido ya estaba medio loco, hasta el extremo que los inquisidores temiendo por su vida acordaron ponerle un compañero de celda, Diego Cedillo. Y aquí comenzó el drama, pues por la noche Melchor quiso estrangularle y en

\footnotetext{
115 Chinchilla Aguilar, E., La Inquisición en Guatemala. Guatemala 1953, pág. 237.

116 FISHER, J., “lberoamérica colonial», Historia de Iberoamérica. 3 v. Madrid 1990, II, págs. $551-661$.

117 Blázquez Miguel, J., Eros y Tánatos, págs. 197-204; Ibidem, Castilla-La Mancha, Magia, págs. 107-113.

118 Riva PALACIO, V., Memorias de un impostor: don Guillen de Lampart, Rey de México. 2. ${ }^{a}$ ed. 2 v. México, 1976; González Obregón, L., Don Guillén de Lampart. La Inquisición y la independencia mexicana en el siglo xvili. París, etc, 1908.

119 BlázQuez Miguel, J., Eros y Tánatos, op. cit., págs. 200-202; Ibidem, La Inquisición en Albacete. Albacete 1985, pág. 94.
} 
defensa propia fue golpeado por Diego con una piedra, lo que le causó la muerte. Como el destino de Melchor parecía unido a la tragedia, ésta se manifestó en forma de remordimientos y a los pocos días Cedillo apareció ahorcado en su celda ${ }^{120}$.

Al margen de cuanto anteriormente hemos escrito, hay una faceta especial que en no pocos casos se encuentra intimamente ligada con la hechicería, hasta el extremo de que en la mayoría de los casos sus protagonistas son los mismos. Nos estamos refiriendo al curanderismo y a esas personas que poseían bien una supuesta virtud para sanar, bien conocimientos empíricos que conducían a resultados no soñados por la medicina oficial, y a las que recurrían todas las clases sociales ${ }^{121}$.

En América los indios tenían una medicina ciertamente avanzada, pero su característica principal era el ritual mágico que la envolvía ${ }^{122}$ y ya los primeros comisarios de Chile procesaron al gobernador Martín Ruiz de Gamboa, que permitió que una curandera india tratase a un cacique enfermo ${ }^{123}$.

La ancestral creencia en el mal de ojo no estaba ausente en Indias ${ }^{124}$ y los medios para combatirle no diferian mucho de los de la Península, excepto algún que otro caso específico, como el de la mulata Ana Vega, de Puebla de los Ángeles, que para prevenirlo utilizaba cabezas de escorpión. Era ésta una mujer que ganaba sus buenos dineros ejerciendo de curandera y una especie de ungüento amarillo - que para todo vale y para nada sirve- debía de ser el que confeccionaba a base de manzanilla, hierba de Santa María, hierbabuena, eneldo, hinojo, zempoalaúchil y liquidámbar, todo bien frito y colado, aunque para los dolores de tripas usaba uno especial, cuya receta era pelo iloche bien molido con sal y manteca y hervido en agua muy caliente ${ }^{125}$.

120 AHN, Inquisición, libro 1065, fols. 365-367: CASTANIEN, D.G., "The Mexican Inquisition Censors a Private Library". The Hispanic American Historial Review, XXXIV, 1954, 3, págs. 374392.

121 Blázquez Miguel, J., Castilla-La Mancha. Magia, págs. 183-218.

122 Aguirre BeltráN, G., «La medicina indigena", América Indigenista, VII, 2, págs. 107-127, TfENS, M. B., "Arte curativo de las enfermedades, farmacia y hechiceria", en Brujeria y el nahualismo en la Nueva España. Chiapas 1954; GuerRA, F., La medicina precolombina. Madrid 1990.

123 Encina, F. A., Historia de Chile. Véase Santiago de Chile, (s. a.), III, pág. 125.

124 Un detallado estudio de estas creencias, con amplia bibliografía, en BLÁzQUEZ M|GUEL, J., Castilla-La Mancha. Magia, págs. 147-182.

125 RELACIÓN del tercero autor particular de fee que el Tribunal del Santo Oficio de la Inquisición de los Reynos, y Provincias de la Nueva España, celebró en la Iglesia de la Casa Professa de la Sagrada Religión de la Compañía de lesus a los Treinta del mes de Março de 1648... México 1648. 
Los curanderos, por lo general, utilizaban hierbas para sus curaciones y en cada país han de adaptarse, lógicamente, a las que hay. Al margen de otras hierbas, fue el peyotl el que más intrigó a los inquisidores cuando oian los relatos de quienes habian experimentado en sí sus efectos, como una paciente del negro amoriscado Candelario de Vargas, que declaró haber visto muchas palomitas y que sobre el cuerpo le caían como gotas de sangre ${ }^{126}$.

Algunas curanderas no conocían bien su empleo, por lo que se ayudaban de auténticas especialistas, como hacía Juana Apodaca, Ilamada "La Lozana» ${ }^{227}$, lo que no era el caso de una de las últimas hechicerascuranderas procesada por la Inquisición mexicana, Juana Martínez, en 1794. Cocia peyotl, planta que recogía invocando a la Santísima Trinidad y haciendo tres señales de la cruz, ceremonia que repetía al administrarle a sus pacientes. Nada se hizo contra ella e incluso el sacerdote que la denunció recibió una severa reprimenda ${ }^{128}$.

\section{CIFRAS Y ESTADISTICAS}

De las 584 causas supersticiosas que hemos recogido, vemos que el Tribunal de mayor actividad fue el de Cartagena de Indias, pues él sólo representa casi la mitad de todos los procesos americanos de este tipo ${ }^{129}$. Al igual que en los Tribunales hispanos, el momento álgido de la persecución es hacia los años treinta del siglo XVII, cuando los luteranos han dejado de ser problema y los judaizantes están ralentizados, por lo que el Santo Oficio dirige la vista hacia estos engañabobos acosados por una turbamulta de crédulos clientes, deseosos de cambiar por medios mágicos el rumbo de sus vidas.

Las sentencias, por lo general, no fueron duras y no son comparables en modo alguno con las de las justicias civiles europeas, que no eran remisas en enviar a la hoguera a cuantas supuestas brujas caían en sus manos, al igual que en Norteamérica y no es preciso sino recordar el drama de Salem, por citar el más conocido.

126 AHN. Inquisición, leg. 1732/78.

127 Greenleaf, R. E., "Inquisition in eighteenth Century. New Mexico", New Mexico Historical Review, 60,1985 , págs. 29-60.

128 LEA, H. C., Historia de la Inquisición Española. 3 v. Madrid 1983, III, pág. 589

129 Para un estudio sobre las hechiceras procesadas en este Tribunal, véase la obra de Gouin, CH., L'Inquisition de Carthagène. Blasphèmes et superstitions, 1668-1674. Toulouse le Mirail 1977 (Tesis de Maestría). 
La Inquisición americana no relajó por este delito más que a una sola persona, Guillén de Lampart, y lo fue por motivos políticos, más que por practicar la Astrología; las galeras son prácticamente desconocidas, salvo en algún que otro peligroso reincidente, siendo lo más común los azotes y el destierro.

El tormento, por contra, aunque no muy utilizado, sí lo fue mucho más que en España, donde hubo pocas hechiceras que pasasen por las manos de un verdugo. En México se empleó en algunos casos, como con Isabel Montoya, sin que diese resultado alguno ${ }^{130}$.

En Cartagena sí fue relativamente empleado, sobre todo en momentos de epidemias brujeriles ${ }^{131}$.

No son pocas las mujeres recluidas en hospitales, algunas para que hiciesen penitencia sirviendo a los pobres; las más para intentar curar sus dolientes y enfermos cuerpos. La Inquisición de Lima, por ejemplo, acostumbraba a depositarlas en el Hospital Real de la Caridad, pero, aún enfermas, causaban espanto a los otros pacientes e incluso a los capellanes y mayordomos, que no se atrevían a corregirlas, por lo que las solicitudes para que no las enviasen alli eran continuas ${ }^{132}$.

Este es el trasfondo humano de estas mujeres, esclavas, prostitutas y desarraigadas, que infundieron temores en toda una sociedad y que no era más que desechos humanos que para malvivir tenían que vender sus cuerpos a los hombres y sus almas no al diablo, como se creía, sino a los terrores supersticiosos de una crédula sociedad temerosa e inculta.

Si los hechos supersticiosos representan muy poco a nivel estadístico en cualquier Tribunal español, no es lo mismo en América, pues con sus 584 procesos se coloca en tercer lugar, tras la bigamia y el criptojudaísmo. De todas formas es preciso matizar esta cifra, pues es debida a que el Santo Oficio de Cartagena de Indias, con sus 240 reos, sube su propia estadística hasta un exagerado $24,5 \%$, cifra no alcanzada en ningún otro Tribunal. Lima se mantiene al nivel hispano y lo mismo México, aunque sus 127 procesos no puedo admitirlos y o bien considero que me han faltado procesos por estudiar que se han perdido, o bien pienso que los

\footnotetext{
LEA, H. C., Historia, op. cit. III, pág. 583.

Medina, J. T., La Inquisición en Cartagena de Indias, op. cit., págs. 109 y ss. AHN, Inquisición. Leg. $2199 / 5$.
} 
inquisidores mexicanos nada querían saber de estos asuntos, enojosos y pueriles.

El $31,5 \%$ de los reos son españoles, como es casi natural, pero hay que hacer constar que los negros, esclavos en su mayor parte, alcanzan un elevado $18,6 \%$ y los mulatos el $16,6 \%$, todo muy de acorde con el medio social en que sus vidas se desarrollaban. 